10.1515/ausfm-2015-0003

\title{
The Tableau Vivant as a "Figure of Return" in Contemporary East European Cinema
}

\author{
Ágnes Pethő \\ Sapientia Hungarian University of Transylvania (Cluj-Napoca, Romania) \\ E-mail: petho.agnes@gmail.com
}

\begin{abstract}
The paper analyses the re-conceptualization of the intermedial trope of the tableau vivant in recent East European cinema through several examples from Hungarian and Russian films directed by György Pálfi, Kornél Mundruczó, Benedek Fliegauf, Béla Tarr, and Andrei Zvyagintsev. The tableau vivant in these films is not conceived primarily as an embodiment of a painting, the introduction of "the real into the image" (as Brigitte Peucker described), instead it appears more like the objectification of bodies as images, and something that we can associate with what Mario Perniola considers the "sex appeal of the inorganic" or "the Egyptian moment in art." As such, the tableau becomes a powerful agent in generating metanarratives, offering a blueprint for a "big picture," a comprehensive vision of the world (reinforced by recurring mythological themes like the genesis or the end of the world, the loss of Paradise, etc.). We may connect this feature of these tableaux vivants, therefore, to what Lyotard termed as the "figure of return," and to the reconstructive tendencies of contemporary post-postmodern art. ${ }^{1}$
\end{abstract}

Keywords: tableau vivant, embodied painting, East European cinema, the sex appeal of the inorganic, Lyotard's acinéma.

\section{Embodied Paintings and Bodies Objectified as Paintings}

Steering away from all the mainstream "new waves" that emerged in post-communist cinemas - and in some ways loosely connected to the tradition defined by the cinematic poetry of Andrei Tarkovsky, the ornamentalism of Sergei Paradjanov, and perhaps, the bizarre surrealism of Wojciech Has - we can distinguish several undercurrents in recent East European ${ }^{2}$ cinema consisting of films that are

1 This work was supported by a grant of the Romanian Ministry of National Education, CNCS - UEFISCDI, project number PN-II-ID-PCE-2012-4-0573.

2 Eastern Europe as a geo-political and cultural term is used in this case in its widest possible meaning, including Russia and the Baltic states of North-Eastern Europe, as well as so called Central Europe and South-eastern Europe. 
somehow obsessed with the sensual and intellectual charge of the autonomous, painterly image (whether it is an image resembling a painting, or an image that seduces our senses appearing as a palpable texture instead of a detached screen). This is a tendency that is perhaps most palpable in the manifold revitalization of the trope of the tableau vivant and a post-cinematic aesthetics trading in the drive of the narrative for the compelling visual attraction of carefully crafted imagery. While the critical and theoretical reception of contemporary East European cinema repeatedly focuses as a default option on issues of time, space and identity reflecting on the complex changes brought along by the fall of communism, the disintegration of borders, the rise of new, precarious political constructions, the integration of post-communist states into the European Union, as well as by the growing tendencies of globalization, these "undercurrents" may challenge us to shift our points of view and observe in them an intense fixation on the language of moving images itself, a search for new forms of cinematic pictorialism. We may find, however, that this perspective over the films of these - otherwise very diverse - authors doesn't just redirect our attention towards matters of style and mediality or intermediality in general, but more specifically, it may also reveal different ways how these films manage to dissolve the cultural boundaries between East and West through connecting to particular, universally known references to Western art, as well as through their affinity with more widespread trends in arthouse cinema, while maintaining their distinctively local, historical reference frames, thus operating a new, complex system of "liminalities."

This shift of focus from narrative to visuals and the excessive emphasis on pictorial effects is a poetic strategy that is by no means specific to East European or even to current world cinema. Painterly compositions in a broad sense (descriptive, tableau-like shots achieved with minimum of movement), or recreations of specific paintings in cinema (i.e. tableaux vivants in a narrower, theatrical sense) can be seen as intermedial figures that are present in different ways throughout the entire film history from the frontal, boxed-in tableaux of early cinema ${ }^{3}$ (where they served as a condensation of the narrative), through their decorative, rhetorical/ideological use in Hollywood genre films and so called heritage films, to a means for self-reflexivity and deliberate subversion of the classical narrative in Jean-Luc Godard's or Peter Greenaway's works. In contemporary cinema the re-conceptualization of the cinematic tableau (both

3 This type of shot is usually defined as: "the centred axial long shot, looking at an interior as if at a box set on stage from the centre of the theatre stalls" (see: Ben Brewster and Lea Jacobs, 1998, 38). 
in its wider or narrower sense) often occurs in the context of what has been described as "picto-films," "contemplative/slow cinema" bordering on minimalist, experimental "stasis films," a type of cinema that may already be discussed as an individual paradigm, one that has arguably advanced from being associated with cinemas of the "periphery" (i.e. working outside canonical forms of Hollywood type storytelling and outside powerful centres of the film industry), to dominating a major slice of the repertoires of film festivals. ${ }^{4}$ The examples from East European cinema discussed below can clearly be situated within such a broad context in which both the borders between East European and global art cinema, and the borders between the individual arts have become increasingly porous.

In her book, The Material Image, Art and the Real in Film Brigitte Peucker reminds us that in addition to fashionable parlour games in the $18^{\text {th }}$ and $19^{\text {th }}$ centuries, the tableau vivant also has its origins in pornographic staging of sexually enticing bodies, and considers that it is exactly "in its manifestation of embodied painting" $(2007,30)$, often "as or through the female body," and essentially through "the flesh of the human presence," $(2007,32)$ that the tableau vivant "figures the introduction of the real into the image - the living body into painting - thus attempting to collapse the distance between signifier and signified" $(2007,31)$. There is, however, the possibility of conceiving the tableau vivant as a reversal of this process, and in which embodiment is not erotic in nature (as we see, for example, in all of Greenaway's films) or, at least, not in its conventional sense, but can be related to what Mario Perniola described as "the sex appeal of the inorganic" (2004a) resulting in a fascination with the image itself: not with painting viewed in the form of "real," living, breathing bodies but with bodies objectified as paintings. Accordingly, the tableau does not attempt to merge representation with the real and to collapse the distance between signifier and signified, but emerges as a site for cultivating their distance in the opposition of sensual form and abstract meaning, moving image and static painting, live bodies in action and objects contemplated as a visual display, framing their intricate plays of in-betweenness. "It would seem that things and senses are no longer in conflict with one another but have struck an alliance thanks to which the most detached abstraction and the most unrestrained excitement are almost inseparable" suggests Mario Perniola $(2004 a, 1)$ in a radical new perception of desire, one that brings together philosophy and body, inanimate and animate objects. And while

4 See the online debates over the status of so called "slow cinema." (E.g. Steven Shaviro: http://www.shaviro.com/Blog/?p=891, Mathew Flanagan, http://www.16-9. dk/2008-11/side11_inenglish.htm, Harry Tuttle: http://unspokencinema.blogspot. ro/. Last accessed 15. 07. 2014.) 
this paper does not pursue an overall philosophical investigation, Perniola's concept may point to an area where East European films relying heavily on the technique of the tableau vivant (through different pathways and in their own distinctive manner) connect not only to global stylistic trends in cinema but also, in part, to what can be grasped in the allure of "becoming an image" within contemporary culture on a more abstract theoretical level, as well.

I have found that in some of the films I analyzed, the tableaux vivants proper (i.e. images imitating a particular painting or sculpture) together with other, similar techniques in cinema (static, tableau-like shots, inserts of photographs, and photographic reproductions of paintings) not only reflect on the connections between the visual arts, but, perhaps even more importantly, enclose and cultivate almost irreconcilable extremes: from a sensation of corporeality in pictures coming alive as embodied paintings to the distanciating effect generated by conspicuous artificiality and stylization.

\section{Cadaverous Tableaux Vivants}

The quintessential image framing such antithetical extremes of "things" and "senses" (as perhaps the most puzzling instances in the rhetoric of pictoriality in East European cinema) can be identified in the type of tableau vivant that is, paradoxically, closely connected to the idea of death (the imminence of death, the sight of a disfigured, ailing body), in which a live body is displayed as a corpse, or the other way round, a corpse is presented as an embodied picture, or an object of art made of flesh. The striking still compositions that can be associated with paintings, painterly styles, pictorial photographs, or art installations incorporated by cinema have the rhetorical function of highlighting the grave undertones of a narrative which always leans towards the construction of a more or less overt allegory, either in the mood of tragicomedy and the grotesque, of gritty family drama, or that of a more abstract or lyrical meditation with biblical or philosophical connotations. In each case, in a very different way, the tableau form confers the filmic discourse a degree of constructedness and aestheticism that often emerges in a tense interplay with unsettling subject matters, or in certain cases, even a repulsive naturalism of scenes.

The most extreme example, casting perhaps the clearest mould for this paradigm, offering the most shockingly emblematic image for a typical East European mixture between artificiality and life embodied in a tableau vivant (and also a kind of literal presentation of the desire described by Perniola to become 
an object) can be found in the ending of György Pálfi's Taxidermia (2006). ${ }^{5}$ The film is constructed in the form of a triptych of three satirical episodes, centred on the lives of three consecutive generations (or rather, as one critic called it, "degenerations"6) of men made representative of three distinct historical periods in Hungary: the first part takes us to the generation of the Second World War, the second part revisits the period of Soviet domination, and the story concludes in the present, in a Hungary stripped of any distinctive features, in the clinically sterile environment of an art gallery. Each of these parts can also be seen as a bizarre tale of survival. The survival of social humiliation in a hierarchic society and of the ordeals of war leads to an instinct of animalistic procreation and bizarre sexual proclivities, the survival in "the merriest barrack" of the Eastern Block under Soviet rule in what has come to be known as "goulash communism" takes the form of insane consumerism practiced as popular, national sport, and finally, a "survival" of the fall of communism is achieved through "reinventing" the same degenerate family as an exhibit in a macabre panopticon of stuffed bodies that can be presented as "art,"” moving the characters out of "the communist barrack" directly into an aestheticized freak show displayed for the entertainment of Western art consumers. ${ }^{8}$ Accordingly, each of these constitutes a grotesque caricature of an era through focusing on different activities connected to the body and presented as a kind of performance: magical-realist sex (pushing a penis through a hole in the wall, ejaculating flames, siring a baby with a pig's tail), a twisted gargantuan gorging of food in a speed eating competition and, finally, hyperrealist taxidermy (after having stuffed to death the father's obese belly with food, the cadaverously thin last progeniture preserves the family "heritage," i.e. their own bodies, by mounting them for an installation/diorama). In the grandiose finale we are shown in a harrowingly long sequence of close-ups how the protagonist's body is being eviscerated, stuffed, stitched up and eventually transformed into an artwork (a "body sculpture" or "body installation"), and exhibited in a well-known pose for

5 "The beasts Palfi parades before us are merely caricatures in a pageant, and his abrasiveness hardly conduces to introspection - you're too busy turning away instead of turning inward. Alienation from our bodies, so potent a theme in Cronenberg, here becomes more an excuse for acts of virtuoso gross-out" (Elbert Ventura, http://www.reverseshot.com/reviews/entry/383/reverse_shot_taxidermia.

Last accessed 15. 07. 2014).

6 Peter Bradshaw in The Guardian, http://www.theguardian.com/film/2007/jul/13/ comedy.drama. Last accessed 15. 07. 2014.

$7 \quad$ In this respect the film becomes self-reflexive, as it does not only present a shocking art performance as part of its plot, but Pálfi's work itself can be viewed as a film that has been influenced by and that transgresses towards contemporary (performance) art. This episode is set in Vienna. 
Western art in a trendy, contemporary art gallery (reminiscent at the same time of paintings depicting the martyrdom of St. Sebastian and of the Hellenistic torsos) in front of an audience also posing motionless as a tableau vivant. Steven Shaviro (2012a, 33) called the film "viscerally charged and icily allegorical," and as a whole Pálfi's film is an uncanny combination of social satire and concept art, with shocking, gut wrenching images of the flesh (an imagery that has its source in the meat-sculptures of the contemporary installation artist, Géza Szőllősi, who also served as an art director for the film). The fact that the film substitutes reflection on human history with bodily revulsion, intellectual analysis with disembowelment in the literal sense, manages, at the same time, both to reel in its spectators through creating these fantastically spectacular performance sequences, and to alienate them, as they may also have an irresistible urge to avert their eyes. ${ }^{9}$

Leaving aside the unique combination of the disgusting with the decorative in Taxidermia,${ }^{10}$ on a more abstract level, the tableau vivant displaying a corpse captures the potentially cadaverous nature of all tableaux vivants. As Aura Satz pointed out "the living picture lacks articulation (vocal, physical, and narrative), it has ossified into rigor mortis, and if and when it slackens, this is only so as to shift into the next pose, the next statue, or to snap out of it and back to normal fluid life. The tableau vivant is in fact a temporary cadaver, a presence which has petrified into object" (Satz 2009, 163). Moreover, we can add, quoting Caitlin Baucom's (2014) interpretation of Satz, that the tableau can be conceived as "a cadaver of a cadaver because it hardens into something already dead, referring always to a body image outside of its own." ${ }^{11}$ The taxidermied corpses at the end of Pálfi's film perform this morbidification of dead bodies into other bodies becoming art exhibits, and are highly symptomatic of the almost inhuman detachment, if not always irony, with which some of these films construct their stylized images building on the opposition between "life" and "art," sensual and abstract, fossilizing their human figures into "dead" iconographical forms.

$9 \quad$ The critical reception of the film clearly indicates this divide: enthusiastic reviews alternate with evaluations that find in all of this more fireworks than substance.

10 A feature that is actually shared by another work that was also made with the collaboration of Szőllősi, Opium: Diary of a Madwoman, a feature film by János Szász, made in 2007.

11 See: http://incidentmag.com/issue-1/critical-essays/performative-models/.

Last accessed 1. 09. 2014. We can also note here the long tradition in theorizing the image connected to the idea of death and the dead body: from Régis Debray's (1992) idea of the image as a "domesticated terror" (the prototype of which being the Egyptian mummification of the body, an opposition to the decomposition of the body in death through its recomposition as an image), to Barthes's or Bazin's views of photography as death mask. 
We see this also in paraphrases of Andrea Mantegna's and Hans Holbein's dead Christ [Figs. 5-6] that have become a surprisingly recurring motif in contemporary East European and Russian cinema. The examples include the Hungarian Kornél Mundruczó's unconventional opera-film, Johanna (2005) set in the depressing location of a run-down East European hospital, in which a drug addict woman, having been brought back to life from the stage of clinical death, becomes a kind of modern-day, provincial Saint Joan who nurses hopeless patients back to health by offering them sex as an act of mercy, only to be killed and discarded from the medical facility like trash. The film contrasts the dismal artificial world of the hospital where people are strapped to beds and connected to machines with the supposed naturalness of the sexual act, the abject sight of the sickly bodies with the rendering of dialogues as opera arias or recitativoes, and with the stylized colour palette of the images enhanced by sequences presenting the listless, lying bodies as paraphrases of the Dead Christ [Figs. 7-8], while making Johanna resemble Vermeer's painting of The Girl with the Pearl Earring in a mixture of aestheticism, absurdity, and pathos that the viewer may find just as disturbing as Pálfi's combination of nauseating sarcasm and stunning visuals.

Mundruczó reprises the allegorical contrast between the unnatural and natural, cultural and instinctive in his next film, Delta (2008), in which the male protagonist (played by the renowned world music violinist and composer, Félix Lajkó, and as such, bringing a set of complex associations to the role ${ }^{12}$ ), returning home after a long time, engages in an incestuous affair with his sister (having a telling name, Fauna) with tragic consequences amid the "primitive" and harsh realities of the colony of fishermen, and in which again, we find a paraphrase of Mantegna's famous painting. This time, the elements of the painting and of the Biblical situation are reversed: it is not the Virgin Mary leaning over the body of Christ overcome by grief, but we see the frail body of the innocent young woman lying feverishly on a bed in the small cabin the siblings have built on the water, and after having been raped by her stepfather it is her Christ-like brother who takes care of her, who wraps her in a damp cloth (arranging her in the reclining position we've come to known from Mantegna's famous canvas), and sits by her side [Figs. 9-10]. The tone here is more elegiac than social critical; the beautiful shots of the Danube Delta paint a mythical backdrop, a kind of lethal Paradise, where the unravelling tragedy is subdued by the gorgeous cinematography. The

12 Félix Lajkó, a former child prodigy, has become known as a world music virtuoso with an intensive style of playing the violin or the zither and with an air of mysticism. His repertoire includes a mixture of almost anything from folk music to rock, classical music, or jazz improvisations. 
image reminiscent of Mantegna's Christ is prepared slowly as the male protagonist carefully arranges the sheet around the woman's body, and the tableau emerges seamlessly from the flow of other picturesque compositions. There is no shock value in its appearance, the association is subtle, the image becomes like a fading palimpsest: the familiar pose and composition barely resurfacing within the cinematic mise en scène.

A similar melancholic mood prevails in Béla Tarr's last film The Turin Horse ( $A$ torinói ló, 2011) ${ }^{13}$ in which man is set against the raging elements, and which also unfolds an allegorical story: staging through a slow, minimalist narrative and a series of photographic tableaux, how - in a reversal of Genesis - the world comes to an end. Death acquires cosmic and philosophical proportions and is prefigured by presenting the protagonist both as the embodiment of Mantegna's and Holbein's dead Christ [Figs. 11-12]. These paraphrases not only constitute in their austere simplicity a sublime figuration of lamentation for the end of mankind but also underscore Tarr's extraordinary attention to how each frame is constructed. The elements are simple, the film is built using only a few building blocks (an old man, a daughter, a horse, a house, a tree), each scene is like a slowly moving photograph within a video installation, there is nothing left to chance. ${ }^{14}$ And while there is a heightened sensation of photographic realism in the details (e.g. we see the fine grain of the wooden table, the rough texture of the plain clothes, etc.) everything is stylized and far from lifelike, instead of a story with characters revealing psychological depths there is only a sequence of repetitive actions, and bodies framed and reframed as images, and, ultimately, images fading away.

Benedek Fliegauf's Dealer (2004), presenting the last day in the life of an unnamed drug dealer, conceives the cinematic image in the same vein as Tarr. The mostly uneventful narrative is presented in a slow pace with static images of cold and eerie beauty, ${ }^{15}$ and deals primarily with feelings of loss and emptiness. The dialogue is scarce, the protagonist moves in spaces that are either cluttered

13 The idea of the film comes from the story of Nietzsche's final breakdown as he supposedly witnesses the brutal whipping of a horse in Turin. The film constructs an epilogue to this anecdote which is used as a motto to the film.

14 The behind-the-scenes documentary made during the shooting of the movie (Tarr Bela. I Used To Be a Filmmaker, directed by Jean-Marc Lamoure, 2013) presents how the whole setting of the film was constructed to the tiniest detail around the lonely tree at the hilltop.

15 Fliegauf is also the author of a successful experimental film, titled Milky Way (2007) built entirely of individual tableaux, without conventional narrative, without dialogue, in which the sequences shown consecutively can be screened as an essay film, or, shown simultaneously, they can be exhibited in the form of a multichannel video installation in art galleries. 
with junk or seem vacuous and sterile, accompanied by metallic, trance-like nondiegetic music. The film concludes with a long sequence in which the protagonist takes an overdose of drugs in a fitness salon and climbs into a tanning bed as if it were a coffin. As he lies down, his stretched out body, seen through the narrow opening of the machine, is reminiscent of Holbein's elongated corpse of the dead Christ [Figs. 13-16], resulting in a powerful image crossing modern technology with classical iconography, an ironic view over the cult of the body ${ }^{16}$ and a melancholic awareness of the hopeless isolation and transience of the body. The sequence is then prolonged and the image of the tanning bed moved further and further away from the viewer against a dark background, until it disappears like a spaceship within the infinite black universe or is reduced to a dot on the screen before its final blackout and the film itself shuts down like a machine. Death appears at the same time as mechanical (as a final disconnection from the world), grotesque (self-destruction in a fitness salon), and transcendental. The cold, artificial light cast over the body of the protagonist in this pose retroactively sheds a different light over the whole story, elevating it both from its realistic portrayal of contemporary urban ennui or desolation, and from a mere exercise of style, by capturing the moment of death as an enigmatic tableau vivant eliciting multiple associations among which the famously humanized depiction of the dead Christ is also one, but not exclusive, possibility.

Perhaps the most complex use of the reproduction of Mantegna's painting can be found in the Russian Andrei Zvyagintsev's debut film, The Return (Vozvrashcheniye, 2003), where it becomes not only a clearly marked vantage point that doubles the reference frame of the otherwise realistic narrative, suggesting the possibility of an allegorical reading, but it also makes the viewer prepared for further, less obvious biblical motifs or cinematic quotations, ${ }^{17}$ and initiates an intricate play between images and media.

The film is about two teenage boys whose father returns after a long and unexplained absence. ${ }^{18}$ One day, coming home after playing with their friends,

16 This irony is underscored also by the posters displaying virile bodies hanging on the wall contrasting with the association with Holbein's painting of the emaciated, dead body of Christ.

17 The viewer familiar with Tarkovsky's films may find several scenes paying homage to the master of "sculpting in time" alongside images reminding us of essential works of Antonioni or Kieslowski, as the film unfolds, through a consistently pictorialist cinematography, a series of impressive photographic tableaux.

18 The film never reveals why the father has been away, the boys and the spectators can merely speculate: whether he has been in jail, has fought as a soldier in the Afghan war, or has just neglected his family for several years. 
out of the blue, their mother tells them that their father is home and asleep; they go into the house and find him in the bedroom in the posture that we know from Mantegna's painting. The sons contemplate his appearance in awe standing in the doorway of the room where his foreshortened body is lying on the bed as a strange exhibit in a glass cage [Figs. 17-18]. As the boys don't remember him, they run off to compare the photo they have of him with the image appearing to them in the bedroom. The father, who has until now existed for the boys only as a figure in a photograph (tucked away in the attic in an album illustrating biblical scenes, placed in the category of symbolic images), ${ }^{19}$ materializes in a form duplicating a painting, as a body, an image, an idea - also, perhaps, as an incarnation of the myth of the Father as the embodiment of virility and of Russia itself. ${ }^{20}$ When he awakes, he appears to be distant, unsympathetic, eager to assert his paternal authority and enigmatic. He sits down to a final meal together with the two women (mother and grandmother, who have both been left outside the frame reproducing the painting earlier) and his children in a shot reminiscent of Leonardo da Vinci's Last Supper [Fig. 21]. Then he sets out on a mysterious voyage, a fishing trip together with his sons. [Figs. 22-24.] The story unfolds within a mythical time frame (beginning with Sunday, when the father-creator rests and ending with Friday, when the Christ-like father dies), along clearly symbolic axes: horizontally (undertaking a symbolic voyage of initiation, as the father takes the boys on a road trip) and vertically: the acts of ascent, descent, rise and fall. The film is framed by the image of a tower: at the beginning wee see the younger son being too afraid to dive into a lake from it, at the end, being angry with his father, the same boy climbs another tower threatening to jump down, and as he attempts to go after him, the father accidentally plunges to his death. At which point his sons are faced with the difficult task of acting as grownups dealing with the lifeless body of their father and driving home on their own.

The title of the film, The Return, may be interpreted both literally, referring to the father who returns to see his two teenage sons, and symbolically, given that the film introduces the sleeping father as the replica of the dead Christ and

19 The photo [Fig. 25] is kept in an album illustrating scenes from the Old Testament (resonating with the idea of fatherhood): as the boy leafs through the book we see the image of God as the creator of the Earth contemplating his work, a depiction of the story of Abraham's sacrifice (perhaps indicative of the boys' apprehensions about their father's intentions), etc.

20 Accordingly, Zvyagintsev's film can be interpreted as a parable of post-Soviet Russia, which, having lost its great historical Father figures of undisputed authority has to cope both with their loss and with the "return" of such figures in different forms, only to repeatedly experience their inadequacy and unreliability. 
presents events leading up to his actual death. The death of the father, in this way, can be seen as a return to this initial state (the parallelism is striking: the corpse of the man lying in the boat is shown from the same angle as we saw him lying on the bed imitating the Mantegna painting, [Figs. 18-19] and the boys are left with a similar, if even more horrified look on their faces as the boat suddenly begins to sink). So it is actually the loss of the father that returns. But while the body of the father disappears in the murky water of the lake, and the impression of Mantegna's painting is washed away by the photogenic layer of the waves within the cinematic frame [Fig. 20], the power of the "image" itself is reinstated and reinforced. ${ }^{21}$ What has been lost in painting is now regained in photography. The film ends with a series of photographs [Figs. 26-28], in which - except for the very last frame - the father is absent, yet we are now aware of his existence either "off space" (as we remember the scenes when the photos were taken) or behind the camera (in the old photos that we presume he took of his wife and infant sons). These final photographs used as a substitute for the diary of the boys, contrast the performativity of the instantaneous, personal snapshots (being singular, subjective, incidental), and imprints of bodies in motion with the constructedness, stasis and symbolical weight of pictorial iconography manifest in the explicit tableau vivant scene, as well as with the sensuous elements of the moving image in the carefully framed photographic shots [Figs. 22-24] or in the recurring landscape tableaux of the film. Thus the film rounds up different possibilities of people becoming images and images moving from one medium onto another: from the art historical "aura" and symbolism of the Mantegna painting, and the enigmatic cinematic embodiment as a tableau vivant, the image of the father is carried to other associations with drawings illustrating the Bible, to frames of pictorialist cinematography (which delight the eye but only enhance the enigmatic character of the father, whose aestheticized images do not compensate for the fact that his actions remain unexplained ${ }^{22}$ ), and finally to the intimacy of the family photographs. In this way, by foregrounding both the symbolic value of images and their performativity in our lives (how we are affected by them, how

21 I am using the term "image" in the sense described by Joachim Paech ("the representative surface that $[\ldots]$ can be detached from the picture and reproduced in many ways with different media properties"), differentiating it from the notion of "picture" (understood as a "real-world object"). (See Paech 2014, 32.)

22 The photogenic framing of the father and sons from the perspective of the small hut on the lake shore seen in Fig. 24 may exemplify this well. The father brings the boys here to retrieve a small wooden box, but we never see the content of this box or find out what lies inside, because the father dies, and the box sinks with him to the bottom of the lake. 
we interpret the world through them, how their signification may puzzle us, or how we may affirm ourselves through their various palpable forms), the allegory is as much about our indissoluble, intimate relationship to images, accordingly, about the relationship between image, body and differences in medium (painting, film, and photography), as it is about oedipal rites of passage standing in for contemporary traumas in a post-communist society.

Zvyagintsev's next feature film, The Banishment (Izgnanie, 2007), expands the theme of the loss of the father into the disintegration of the traditional family, the loss of the mother, the loss of "faith," 23 the banishment from "paradise," and makes this metareferential layer even more complex with frames composed like paintings, biblical symbolism, and with photographs counterpointing both filmic images and paintings in a dreamlike narrative. Among the many references to paintings there are a couple of examples which seem more relevant for this line of thought. The first is a kind of mise-en-abyme: in one of the most powerful sequences of the film we see just before the protagonist's wife undergoes an abortion, how a group of children are working on a jigsaw puzzle, fitting together pieces reproducing Leonardo da Vinci's Annunciation [Fig. 29]. The picture is dismembered and spread out on the floor, and as the camera films them from above, the children are not only made part of the ensemble, but they are incorporated within the pattern, overlaid as images over images. The quotation is explicit, it is not a cinematic tableau vivant reproduction, the picture alludes, however, to the crucial element in the plot (the possible birth of a child whose father is unknown) emphasizing the possibility of a symbolic reading, ${ }^{24}$ and reflects a salient feature of the visual style directing our attention to the recurring static frames that constitute jigsaw puzzle-like tableaux in the film [Figs. 30-32] or in which different kinds of images are laid on top of each other [Fig. 33-34]. Mantegna's image of the dead Christ, which was so accurately reproduced and placed at the gravity centre of The Return, seems to haunt this film, as well, as elements of the painting resurface in two scenes. In both cases the bodies we see are not dead but in extreme shock: in a reversal of the position of the body we see the father (played by the same actor, Konstantin Lavronenko) stricken with grief, as he collapses after the death of his wife with his face down; and in the flashback

23 As many reviewers have noted this is emphasized by the fact that the woman is called Vera (the word "vera" meaning "faith" in Russian).

24 This is reinforced by further quotations in the film. E.g. in a following scene, in which the children are read from the Bible, the bookmark shown in the close up also reveals a fragment from Masaccio's painting, the Expulsion of Adam and Eve from Eden, a pictorial reference to the title and the main theme, the banishment from Paradise. 
sequence we see the wife in a similar position as Christ in the painting with her feet towards the viewer after the attempted suicide [Figs. 35-36]. Focusing this time more on the figure of the woman who is depicted with a dense mesh of pictorial references [Figs. 37-48] $]^{25}$ the film draws a similar circular trajectory from filmic presence, painterly stylization to the photograph as a recording of the moment and object of memory (and back) to the one seen in The Return, offering a synthesis in the photo of Vera and her two young children captured in the pose paraphrasing Da Vinci's Virgin and Child with St. Anne and John the Baptist (1499-1500) [Figs. 39-40]. As such, if Pálfi's use of conceptual "body horror" ${ }^{26}$ in Taxidermia can be positioned at the extreme of morbid satire (and a narrative literalization of contemporary art's fetishism of bodies exhibited as objects), Zvyagintsev's films gracefully weaving together painting, cinema and photography, may be placed on the other pole, as examples for a poetic use of "embodied images" as "embodied ideas."

\section{Nostalgia for "the Big Picture"}

Regarding this type of films perhaps the most important question is how we should interpret this highly rhetoricized/allegorical mode of expression. Is it a mere extension, an excessive repetition of the modernist models of abstraction that critics usually associate to such films? ${ }^{28}$ Should we attribute the phenomenon to Eastern Europe's peripheral status against Western Europe and global capitalism (taking into account Jameson's highly controversial assertion about the connection between the allegorical way of expression and "third-worldish"-ness ${ }^{29}$ ) and to

25 This excess of pictoriality surrounding her is emphasized by the very last image [Fig. 34] that we see of her is her figure standing in front of a giant painting on a wall and blending in with the forms of the graffiti (an image, that reiterates with "secular" forms the structure of the scene where the children work on the puzzle of Leonardo's Annunciation).

26 This is Shaviro's syntagm characterizing the film (2012a).

27 See a quotation from Zvyagintsev's interview in the Rossiyskaya Gazeta published on November 21, 2006: "the father was not simply, and not only a concrete person, but also a certain function, the personification of some concept. [...] The beauty of the world [...] is expressed through the battle in the world of ideas." Source: http://366weirdmovies.com/the-banishment-2007/. Last accessed 15. 07. 2014.

28 Jancsó's stylized parables and highly artificial visual style are usually invoked in connection with these Hungarian directors' preference for the allegorical mode and Tarkovsky or Bergman are usually quoted as precursors for Zvyagintsev (who himself notes the even more determining influence of Antonioni instead).

29 Cf. "All third-world texts are necessarily [...] allegorical, and in a very specific way: they are to be read as what I will call national allegories" - he contends - abolishing "the radical split between the private and the public, between the poetic and the 
the perpetuation of frustrations caused by social and political crises that pushes artists towards an abstract, fragmented style and the construction of parables? ${ }^{30}$ In an insightful analysis Hajnal Király ${ }^{31}$ speaks of the sublimation of crisis through beauty and the proliferation of the tableau-like compositions in recent Hungarian cinema corresponding to the extended concept of anamorphosis as the emergence of the Lyotardian "figural" within the discursive order of the narrative as a complex symptom of melancholia (as described by Julia Kristeva), and also as a form of cinematic mannerism. Or we may find in this emphasis on aesthetic stylization of individual images and in this repeated reference to masterpieces of European art the gesture of offering Western audiences tales told in the manner they expect from these cinemas, which, following the heritage of "various postwar national new waves" - considering themselves, and being considered by others superior to industrial films of their time - in the words of Randall Halle (2010, 303), have become "associated with high cultural film art," and in which, therefore, universal themes, references to art history and Christian imagery can be expected signs of sophistication, and these easily recognisable references can facilitate connections to a wider cultural and artistic heritage perhaps as manifestations of a self-colonizing instinct. ${ }^{32}$

Then again, we may note that the recurrence of paraphrases of famous paintings alongside "secularizations" of religious iconography, the transmutation of Christian symbols into more universally recognizable patterns that can engage with a multinational audience, and the penchant for tableau constructions (and even for triptych formats) also corresponds to an established practice in video and new media art (see for example some of Bill Viola's controversial video installations ${ }^{33}$ ),

political. [...] The story of the private individual destiny is always an allegory of the embattled situation of the public third-world culture and society" (Jameson 1986, 69).

30 See Xavier's assertion that allegories "often emerge from controversies, conflicts of interpretation, confrontations related to struggles for hegemony in a world in which the shock of cultures and the network of material interests and symbolic systems tend to produce instability in people's lives. [...] Allegory has acquired a new meaning in modernity more related to the expression of social crisis and the transient nature of values, with special emphasis given to its connection with the sense of the fragmentation, discontinuity, and abstraction” (Xavier 2007, 360).

31 This is a forthcoming article in Studies in Eastern European Cinema titled Playing Dead: Pictorial Representations of Melancholia in Contemporary Hungarian Cinema which is highly original in its use of a pictorial model (anamorphosis) offering also a welcome alternative to much of previous scholarships speaking about tableaux vivants (and intermediality) in terms of textuality and writing.

32 See a similar approach in Mónika Dánél’s essay (2012) that offers a postcolonial reading of some of contemporary Hungarian films.

33 This connection between traditional religious art and high tech video installations has been recognized in Bill Viola's The Passions being exhibited in the cathedral of 
so, at least in part, this may prove just as strongly a genuine affinity with what is happening in the field of contemporary art and "expanded cinema." ${ }^{34}$ What seems also plausible therefore is that somehow this extraordinary preoccupation with form and allegorical layers of mediation is not just a displacement, a means to avoid addressing issues in a more direct way, but it can be regarded in connection with experimentation and authorship. As opposed to times of dictatorship, the author of contemporary Eastern Europe no longer needs to adopt the stance of a political dissident forced to speak in arthouse style parables; however, facing the deficiencies of institutional backgrounds in filmmaking (and a total lack of demand for East European genre films on global markets), authorship has become the default mode of creativity (with more or less success), with style offering the possibility to exercise absolute control and, in certain cases, to deliberately solidify the "art" component in the "art film" that may guarantee (with the rise of the festival circuit) a global appeal for these films. Accordingly, the carefully crafted single image, the tableau form in its expanded sense, has been turned into an agent of asserting creative authorship ${ }^{35}$ and authority, of implementing order against chaos.

Moreover, this also happens amid what seems to be a general revival of interest in allegorical forms of expression making use of Christian images and shots devised like paintings identifiable not just across different domains of the arts, but also in a broad spectrum of contemporary fiction films with examples as far ranging as the South Korean Kim Ki-duk's Pietá (2012) and the oeuvre of the Mexican author, Carlos Reygadas, that includes similar allegorical films based on religious and archetypal symbolism and tableaux vivant-like frames (e.g. Battle in Heaven [Batalla en el cielo], 2005; Silent Light [Stellet Licht], 2007; Post Tenebras Lux, 2012), often combining aestheticized images with shockingly violent content.

Berne, in Switzerland, and more recently, in the plasma screen installation of Martyrs (Earth, Air, Fire, Water) - a work that combines the Christian notion of martyrdom with the universal sensual experience of the four elements - in St Paul's Cathedral in London. See also a series of earlier examples in Mieke Bal's (1999) book length analysis of quotations of Caravaggio in contemporary art.

34 The strong link between Pálfi's Taxidermia and today's art world has already been mentioned. This connection with contemporary video art has also been emphasized by András Bálint Kovács with regards to the cinema of Tarr Béla (2013), and can be observed more directly in the artistic practice of some of these filmmakers - like Benedek Fliegauf - who also experimented with video installations.

35 Although having a different vantage point, this may also resonate with Klossowski's concept of the tableau vivant being essentially not a mere derivative image, a copy, but another original, as summarized by Michael Goddard $(2013,46)$, the tableau vivant: "can be understood as a highly perverse reproductive technique that instead of making an original more exchangeable through the multiplication of copies, would render it absolutely singular through its corporeal actualization in 'living material."' 
Despite all their elements of excess and neo-baroque emphasis on visual language and form ${ }^{36}$ therefore these films in East European cinema are neither eccentric, nor isolated examples of recycled imagery, exhausting a pre-existent set of poetic devices and well-known cultural references in ironic language games. On the one hand, I suggest, this inclination towards artificiality in the image, the challenging of the tactile and the embodied aspect of the cinematic medium in the name of visual objectification, and in the form of the shot we can isolate as an autonomous entity resembling a painting, may be linked to what Mario Perniola considers - in the book leading up to his already quoted idea on the "sex appeal of the inorganic" - "the Egyptian moment in art" (1995). In the opinion of the Italian philosopher, we live in an age of the civilization of "things" and of the "look:" while technology seems to take over the human role in the perception of events, and thus assume organic properties, humans deliberately treat themselves as objects. Perniola finds that in the history of humanity "the Egyptian mummy alone evokes such a radical will to become a thing” $(1995,52)$, and that people today are engaged in various processes of self-mummification. Moreover, instead of perceiving the world as a "spectacle," we are more inclined to see it in the terms of a "landscape," i.e. something distant, "incomprehensible, foreign and far away" $(1995,52)$. He also remarks that "tableaux vivants, which appear, alongside dance, to have been one of the ancient Egyptians' favourite forms of spectacle, conveyed just this form of bewilderment and estrangement. [...] They do not attempt a mimetic representation of the action, but focus special attention instead on the particular mimetic physicality of the actor, regarding his/her body as a clothing of flesh [...]. This is a more general feature of ancient Egyptian art, which rather than striving to mimic nature, seeks to create things that are independent of it, endowed with equal dignity and autonomy, that are as things among things” (Perniola 1995, 45-46, emphasis mine, Á. P.). Accordingly, the tableau sequences in these films appear not only like anamorphic details emerging within the cinematic frame, but, as such "things among things," endowed with mysterious "dignity and autonomy." Just think of the way Zvyagintsev's boys look at their father trying to identify the image presented to them in the bedroom with the other picture they have of him, the photograph in the attic, a look representing the perplexity of the spectators themselves comparing the cinematic shot with Mantegna's Christ.

36 Zvyagintsev declared: "For me the hero of a film is the language of that film." Source: Russia Beyond the Headlines, Twelve Seconds of Meditation.

http://rbth.com/articles/2011/05/30/twelve_seconds_of_meditation_12938.html. Last accessed 15. 07. 2014. 
On the other hand, when humans are treated as pictures, flesh acquires the quality of painted texture or sculptural mass, live bodies are objectified as static images recalling familiar elements of famous paintings in these films, there is also another process taking place: the fluidity of the moving image imitating the "flow of life" becomes visibly contained within a certain aesthetic order and structure, chance movements are substituted by the predetermined spatial organization of a particular picture frame, and by the universality of symbol and the endurance of myth. We may connect this feature of these tableaux vivants to what Lyotard termed in his short essay titled Acinéma as the "figure of return," i.e. "the folding back of diversity upon an identical unity," "the repetition and propagation of sameness" (Lyotard 1978, 55). Lyotard speaks of the structure of classical narrative films, that, despite their movements of diversity, tend to return to identical patterns or rhythms shaping films as "productive, consumable objects" $(1978,54)$, as opposed to what he defines as the uncontained movement of "jouissance" seen as pure, "unproductive" "fireworks," and "détournement" in experimental, avant-garde art. In the references to well-known paintings we may also find a similar movement of "rétournement" to a fixed, familiar pattern, repeatedly "absorbing diversity into unity," where this movement is not one that folds cinema, as representation, back onto the world (as in the case of classical narratives), but back onto the interpretive frame of visual arts, channelling cinematic diversity back to recognizable sameness in painting (thus restructuring, reproducing the cinematic image as a "consumable object" for art connoisseur audiences). While, paradoxically, at the same time this may also mean, in a way, a reversal of Lyotard's postmodern principle of replacing grand, universal narratives with small, local narratives: constituting attempts to open up these small, local, often minimalist narratives through the insertion of the "grand image" towards equally grand (biblical, archetypal, mythical) narratives. This movement of "return" symptomatic of a "nostalgia for belonging" or a "nostalgia for tradition" is characteristic of what literary theory has been describing for some time as post-postmodern art. ${ }^{37}$

The repeated reconnection to a universal cultural heritage of "grand images" harnesses their power to coagulate narratives around them, and instead of acting as a disruption, a pause ${ }^{38}$ within the flow of narration, the tableau vivant becomes the prototype of other repetitions and the focal point of circular movements

37 See a good summary of these ideas in the foreword to the volume Postmodernism and After. Visions and Revisions (Rudaityte, 2008) and also in Literature after Postmodernism (Huber, 2014).

38 See Peucker's assessment of the way the tableau works within a narrative $(2007,66)$. 
constructing not so much a linear narrative as offering a blueprint for a "big picture," a comprehensive and suggestive vision of the world (reinforced by the recurring mythological themes of the genesis or the end of the world, the loss of Paradise, archetypal stories of the act of sacrifice, etc.). All of Pálfi's idiosyncrasies and jouissant "fireworks" in Taxidermia "return" to order and to what Lyotard calls "good form" in the symmetry of the timeless triptych structure (where each historical part constructs a grotesque model for the world, birth and creation being at the core of each of them) and in the final display of the body as archaic torso. Zvyagintsev's The Return constructs a circular metanarrative, ritualizing the passage from image to body, and back to image, while in the case of The Banishment - from which Zvyagintsev deliberately removed any sign of particular place and time ${ }^{39}$ - not only most of the tableau-like sequences present grids delimiting pictures within pictures, thus unfolding from parts assembled as a puzzle, but the whole film is presented as an enigma where the viewer should labour on the reconstruction of the whole, big picture, just like the children who reassemble pieces of the reproduction of Da Vinci's painting.

Finally, we might also ask, why do these films refer to these particular paintings and painters? Why this type of paintings at all? Is this a return to pre-modern art history in deliberate opposition to non-figural, abstract art (that so profoundly resonated with the modernist cinema of Antonioni, for example, the model for the pictorial style of Zvyagintsev)? This is what Steven Shaviro suggests in a detailed analysis of Lars von Trier's Melancholia (2011), another recent film envisioning the end of the world and making use of the rhetoric of grandiose tableaux vivants alongside references to paintings. Shaviro interprets the scene in which Justine, the neurotic heroine of the story, replaces a set of abstract pictures with images of well-known figurative paintings by Brueghel, Caravaggio, and others as a clear negation of "modernist abstractions, with their rationally ordered geometric grids [...] emblematic of social control and instrumental reason" in favour of artworks that "show us a world that is unbalanced, opaque to rationality, and cruelly indifferent to human concerns" (Shaviro 2012b, 28-29). I propose, however, that we should not see the same opposition between order and chaos here. The images reminiscent of Mantegna's or Holbein's Dead Christ or Da Vinci's canvases in these

39 While the impression of universality is also reinforced by the use of an international cast and by blending in among quotations of European paintings in the film pictures resembling the works of the American painter Andrew Wyeth. Thus Zvyagintsev trumps Tarkovsky's nostalgia for European art (and through it, for Europeanness) manifest throughout his career with a nostalgia for universal art, or perhaps, more simply, with a nostalgia in cinema for the art of painting (regardless of its cultural context). 
East European films bring their own "grids" and "patterns" to impose coherence (even if this is merely an artistic one), to contain the image and to carry their own set of biblical metanarratives to fold over and frame the story they are embedded in.

At the same time, it is undeniable, that both through the excess of signification enfolded in the paintings, as well as through our own complex bewilderment in experiencing them, through the "shadow" 40 - to quote another of Perniola's concepts - that art leaves behind, "a not so bright silhouette, in which is portrayed anything disquieting and enigmatic that belongs to it" (Perniola 2004b, xvi), they do provide, quite similarly to Lars Von Trier's opus, "dangerous access to archaic and disproportionate forces," (Shaviro 2012b, 29) adding a surplus of weight and a puzzling opacity to these films representative of a post-postmodern aesthetics returning to stories of mythical grandeur, and equally grand images. And while the narratives present the failure of their characters to become heroes of mythical proportion, the films themselves can be viewed as metafictional allegories of this very urge for reconstruction, reinstatement, and re-embodiment of myths. By repeatedly showing us bodies dying into art, and ideas reified as images, these films present us over and over again with rituals of "becoming an image," with a yearning for a reintegration into something universal and lasting, surrendering to the "sex appeal of the inorganic." At the same time along with this movement towards objectification, circular structures, and stasis, however, the tableau vivant also performs, paradoxically, a movement of "détournement," both by placing the cinematic image into the much less stable "shadow of the arts," and by consistently counterpointing the aestheticism of the tableau constructions with a subversive emphasis on bodies and senses, establishing - in Perniola's words, as mentioned before (2004a, 1) - a fragile alliance between "the most detached abstraction and the most unrestrained excitement."

40 The "shadow" is a term that Perniola introduced in his volume of essays, Art and its Shadow (2004b), which substitutes Benjamin's notion of "aura," something that also indicates a major shift: from placing the individual art object with its aura in the centre of the discourse on art to thematizing the complex framework that we perceive around (or more precisely, to use Perniola's words, "at the side of") it instead. As Hugh J. Silverman explains in the Foreword to this book: "shadows 'stand' alongside works of art. They delineate the shape of works of art. And in the shadows come the 'more subtle and refined experience, more intense and attentive to the work'[...] remainders, crypts, shadows are the non-space that accompany art and give it meaning - not the content of the particular works of art that we confront in museums, in catalogues, in books, on the street, and in the electronic media. These shadows accompany each and every experience of art - as trauma, as disgust, as splendour, as grandeur, as exceptional . . . as the sex appeal of the inorganic." (Perniola 2004b, ix-x, xiii.) 


\section{References}

Bal, Mieke. 1999. Quoting Caravaggio: Contemporary Art, Preposterous History. Chicago: University of Chicago Press.

Baucom, Caitlin. 2014. Performative Models. http://incidentmag.com/issue-1/ critical-essays/performative-models/. Last accessed 15. 07. 2014.

Bradshaw, Peter. 2007. Taxidermia. The Guardian. http://www.theguardian.com/ film/2007/jul/13/comedy.drama. Last accessed 15. 07. 2014.

Brewster, Ben and Lea Jacobs. 1998. Theatre to Cinema: Stage Pictorialism and the Early Feature Film. Oxford: Oxford University Press.

Dánél, Mónika. 2012. Surrogate Nature, Culture, Women - Inner Colonies. Postcolonial Readings of Contemporary Hungarian Films. Acta Universitatis Sapientiae: Film and Media Studies vol. 5: 107-129.

Debray, Régis. 1992. Vie et mort de l'image, une histoire du regard en Occident. Paris: Bibliothèque des Idées, Gallimard.

Halle, Randall. 2010. Offering Tales They Want to Hear: Transnational European Film Funding as Neo-Orientalism. In Global Art Cinema. New Theories and Histories, eds. Rosalind Galt and Karl Schoonover, 303-320. Oxford: Oxford University Press.

Huber, Irmtraud. 2014. Literature after Postmodernism. London: Palgrave Macmillan.

Jameson, Frederic. 1986. Third-World Literature in the Era of Multinational Capitalism. Social Text no. 15 (Autumn): 65-88.

Király, Hajnal: 2014. Playing Dead: Pictorial Representations of Melancholia in Contemporary Hungarian Cinema. Manuscript. Forthcoming in Studies in Eastern European Cinema.

Kovács, András Bálint. 2013. The Cinema of Béla Tarr. The Circle Closes. London and New York: Wallflower Press.

Lyotard, Jean-François. 1978. Acinéma. Wide Angle vol. 2: 52-59.

Paech, Joachim. 2014. Intermediate Images. Acta Universitatis Sapientiae: Film and Media Studies, Volume 9: 31-51.

Perniola, Mario, 1995. Enigmas. The Egyptian Moment in Society and Art. London, Verso.

Perniola, Mario. 2004a. The Sex Appeal of the Inorganic: Philosophies of Desire in the Modern World. London, New Delhi, New York, Sydney: Bloomsbury Publishing.

Perniola, Mario. 2004b. Art and its Shadow. London: Continuum. 
Peucker, Brigitte. 2007. The Material Image. Art and the Real in Film. Stanford, Stanford University Press.

Rudaitytè, Regina, ed. 2008. Postmodernism and After. Visions and Revisions.

Newcastle upon Tyne, Cambridge Scholars Publishing.

Satz, Aura. 2009. Tableaux Vivants: Inside the Statue. In Articulate Objects:

Voice, Sculpture and Performance, eds. Aura Satz and Jon Wood, 157-183.

Oxford, New York: Peter Lang.

Shaviro, Steven. 2012a. Body Horror and Post-Socialist Cinema: György Pálfi’s

Taxidermia. In A Companion to Eastern European Cinemas, ed. Anikó Imre,

25-41. Chichester, West Sussex: Wiley-Blackwell.

Shaviro, Steven. 2012b. Melancholia, or, the Romantic Anti-Sublime. Sequence. http://reframe.sussex.ac.uk/sequence1/1-1-melancholia-or-the-romanticantisublime/. Last accessed 15. 07. 2014.

Xavier, Ismail. 2007. Historical Allegory. In A Companion to Film Theory, eds.

Toby Miller and Robert Stam, 333-362. Oxford: Blackwell Publishing.

\section{List of Figures}

Figures 1-4. György Pálfi: Taxidermia (2006). The protagonist's body is being transformed into an artwork and exhibited in an art gallery in front of an audience also posing as a tableau vivant.
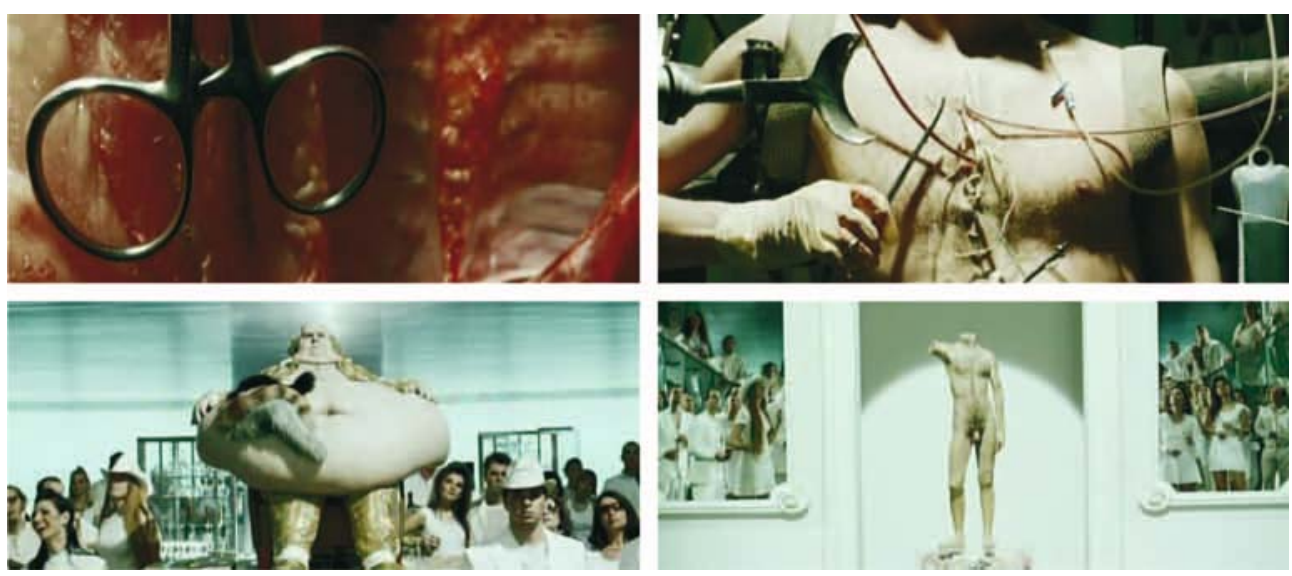
Figures 5-6. Andrea Mantegna: The Lamentation over the Dead Christ (c. 1480) and The Body of the Dead Christ in the Tomb, a sculptural painting created by Hans Holbein the Younger between 1520-22.
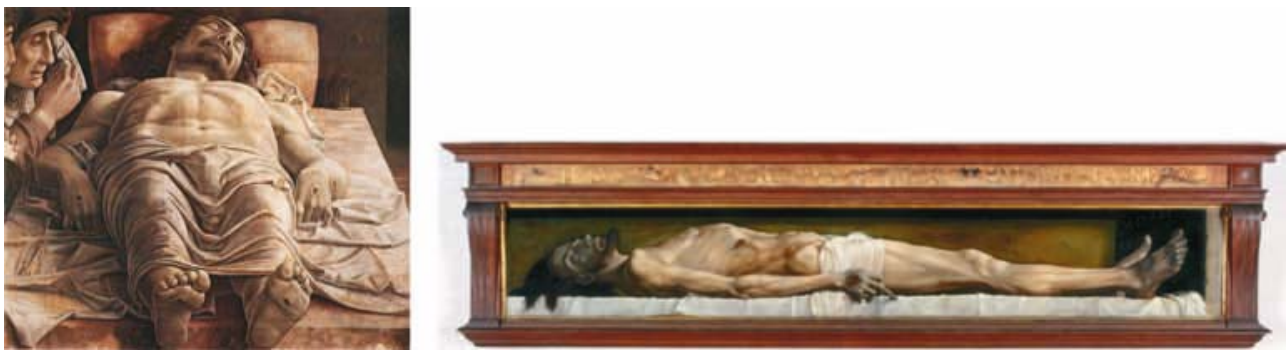

Figures 7-12. Paraphrases of Mantegna's and Holbein's dead Christ in contemporary Hungarian cinema. Kornél Mundruczó: Johanna (2005), Delta (2008), Béla Tarr: The Turin Horse (2011).
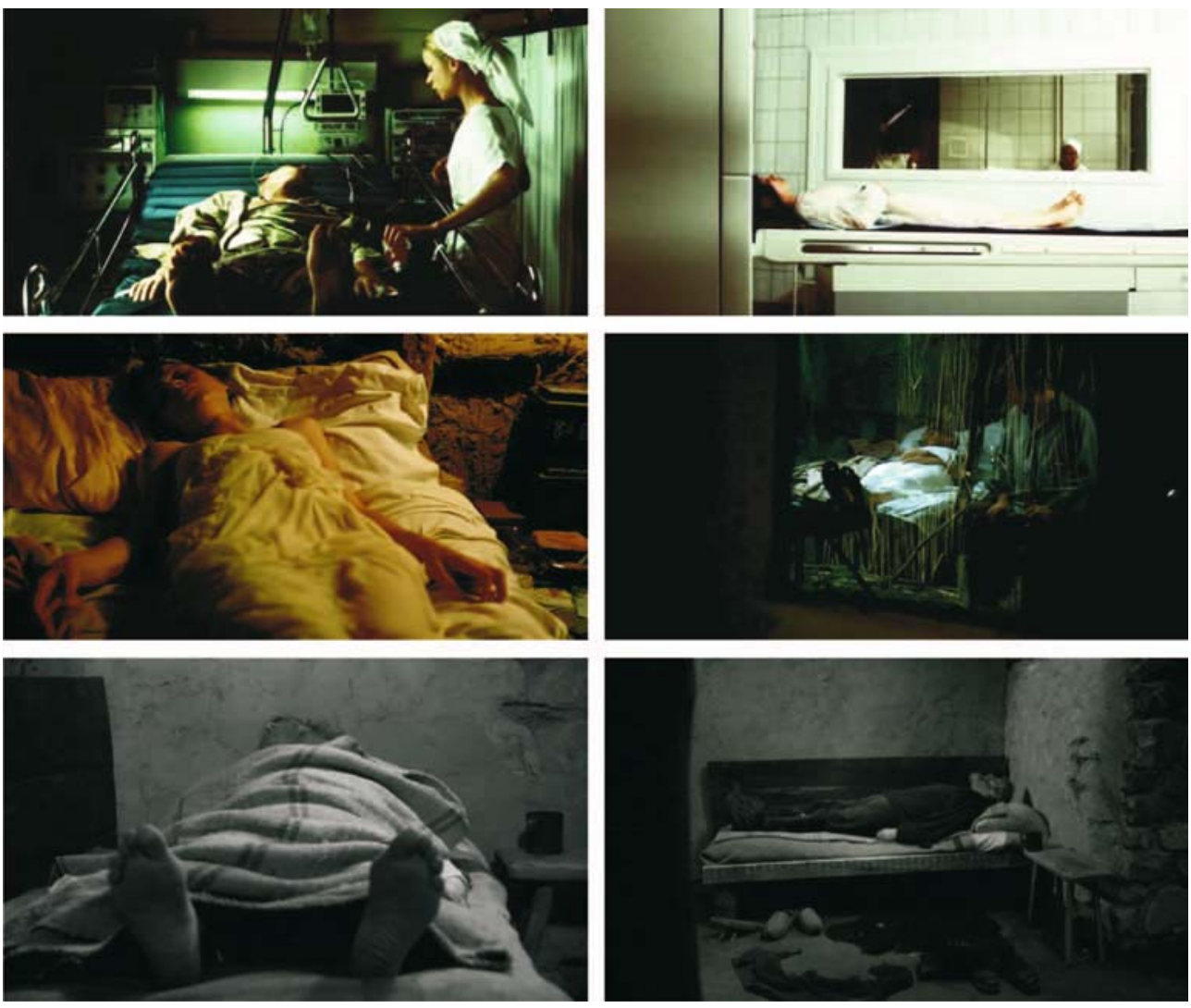
Figures 13-16. The final sequence of Benedek Fliegauf's Dealer (2004): a powerful image crossing modern technology with classical iconography. Death appears at the same time as mechanical, grotesque, and transcendental, while the film itself shuts down like a machine.
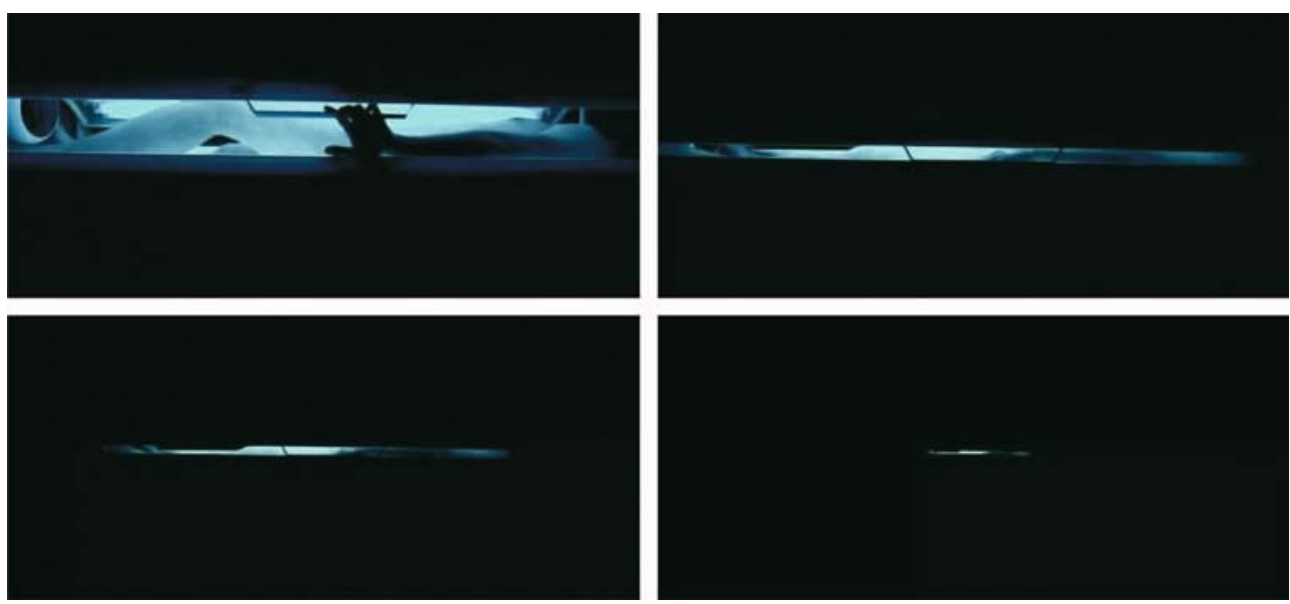

Figures 17-28. Andrei Zvyagintsev: The Return (2003).
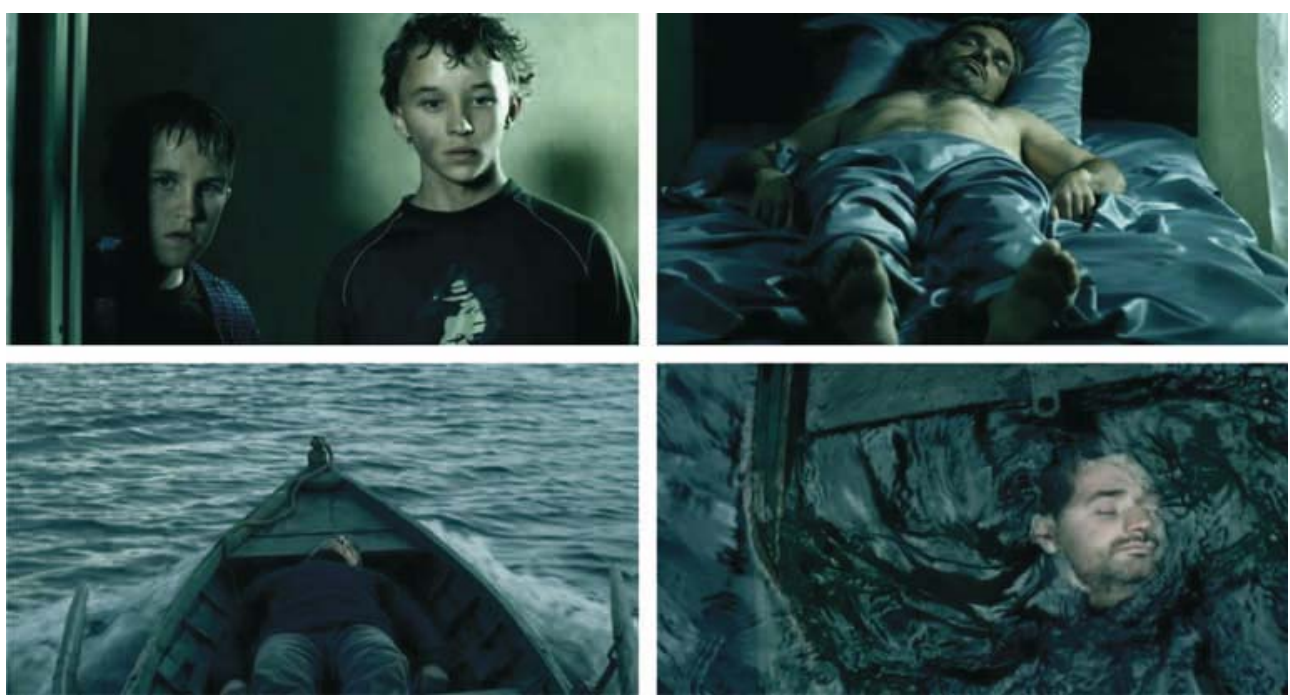

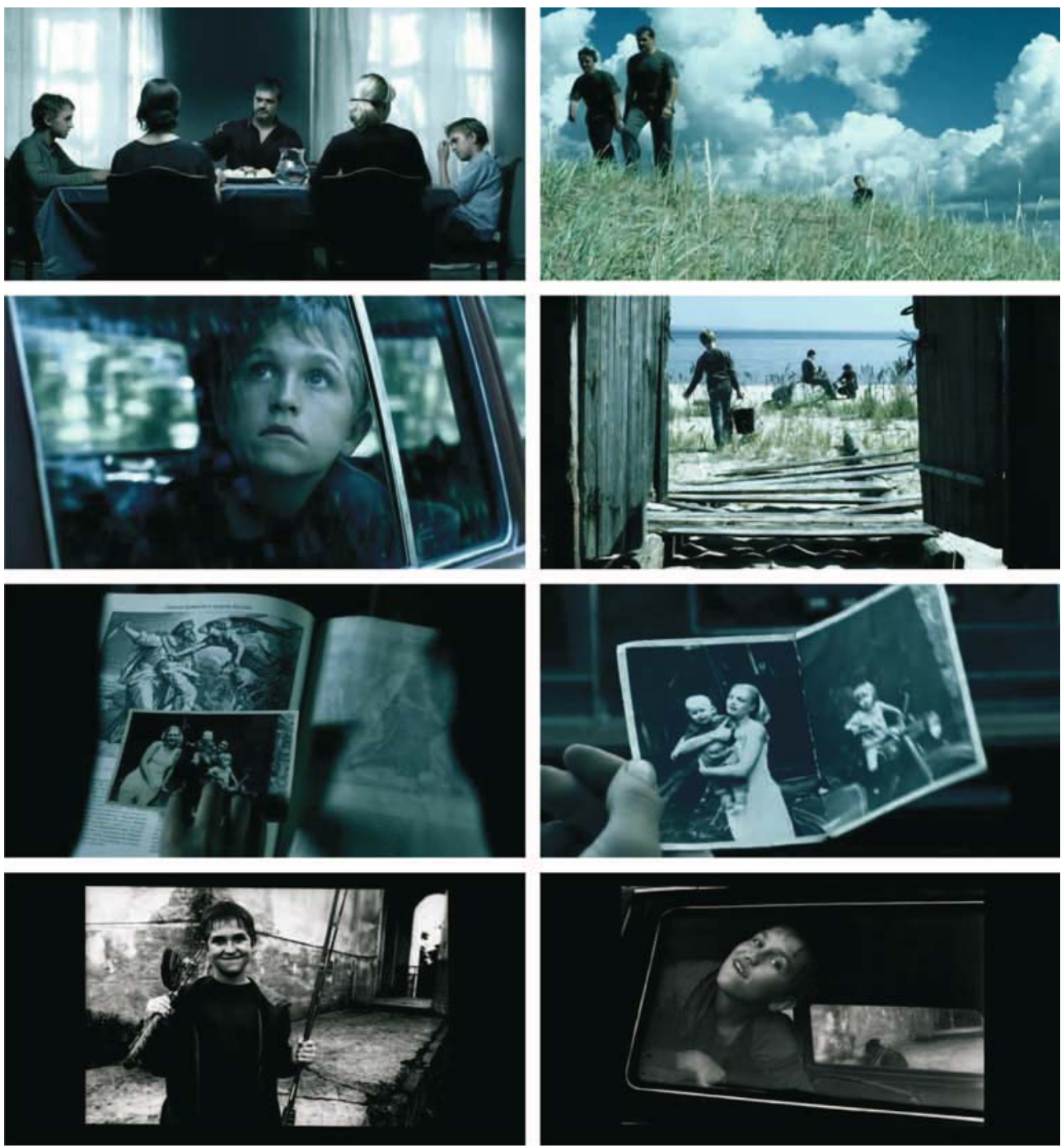
Figures 29-34. Andrei Zvyagintsev: The Banishment (2007), where the jigsawpattern of the puzzle and the structure of images over other images is continued in other scenes.
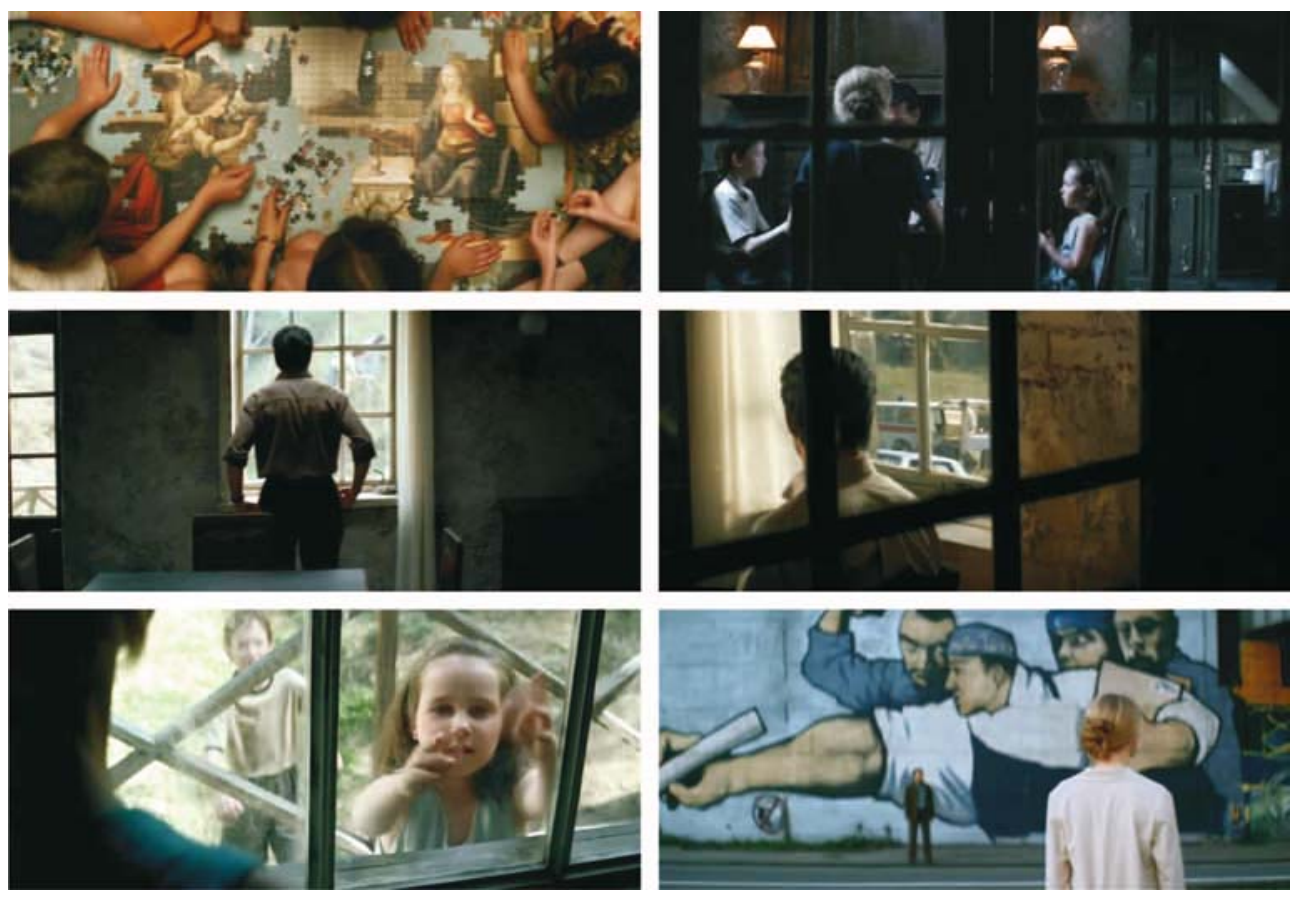

Figures 35-36. Mantegna's image of the dead Christ "haunting" the visual world of The Banishment.
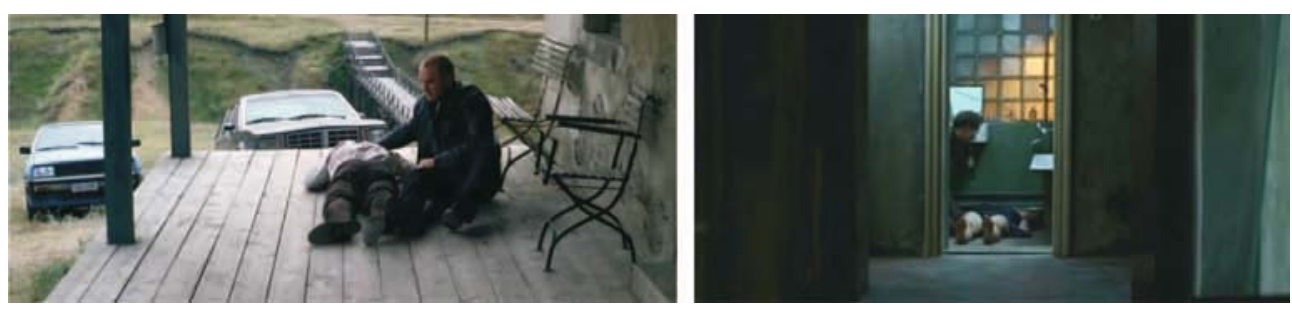
Figures 37-40. The figure of the woman appearing as a painting. Photograph paraphrasing Da Vinci's Virgin and Child with St. Anne and John the Baptist in The Banishment.
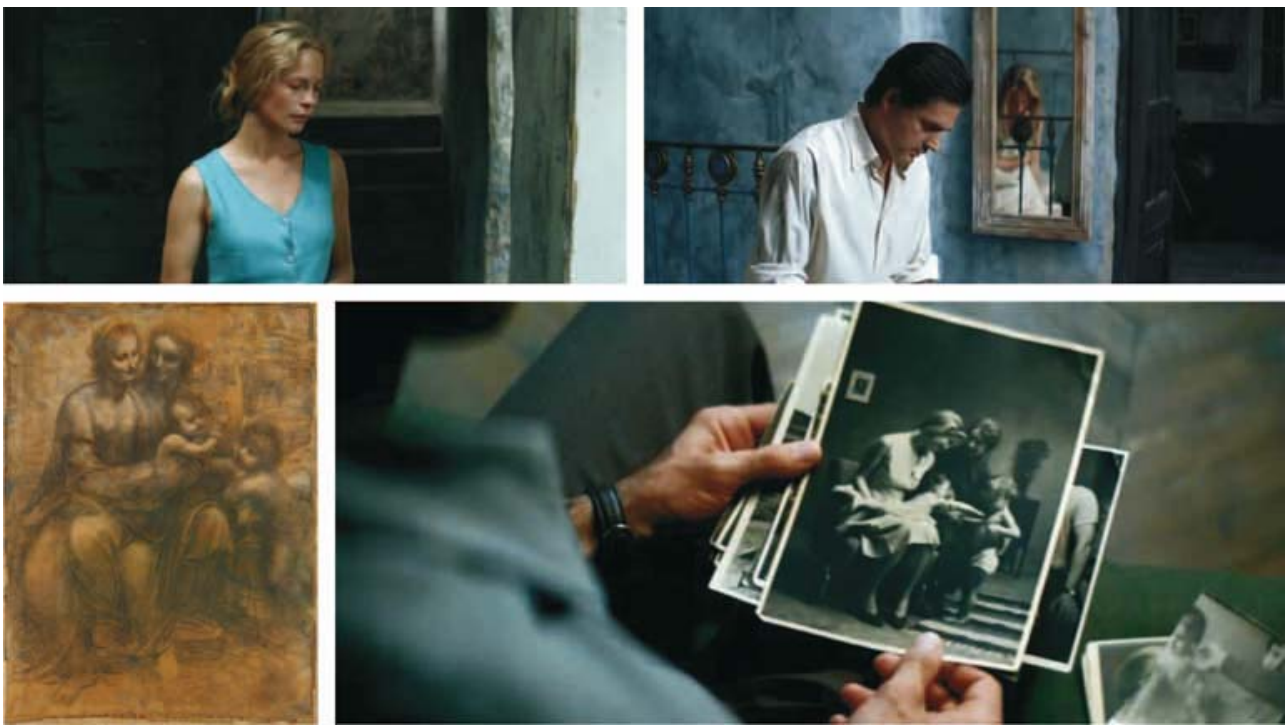